\title{
School-Time Movement Behaviors and Fundamental Movement Skills in Preschoolers: An Isotemporal Reallocation Analysis
}

Perceptual and Motor Skills

(C) The Author(s) 2021

Article reuse guidelines: sagepub.com/journals-permissions DOI: $10.1177 / 00315125211013196$ journals.sagepub.com/home/pms

@SAGE

\author{
Clarice Maria de Lucena Martins ${ }^{1,2}$, \\ Cain Craig Truman Clark ${ }^{3}$, \\ Rafael Miranda Tassitano ${ }^{4}$, \\ Anastácio Neco de Souza Filho ${ }^{2}$ (D), \\ Anelise Reis Gaya ${ }^{5}$, and \\ Michael Joseph Duncan ${ }^{6}$ (D)
}

\begin{abstract}
Little is known of how reallocations of time spent in different movement behaviors during preschool might relate to preschoolers' fundamental movement skills (FMS), a key predictor of later physical activity (PA). Thus, the aim of this study was to examine (a) whether preschoolers' school-time movement was associated with
\end{abstract}

\footnotetext{
'Research Centre in Physical Activity, Health and Leisure, Faculty of Sports, Porto University, Portugal

${ }^{2}$ Research Centre In Physical Activity, Health and Leisure, and Laboratory for Integrative and Translational Research in Population Health, Porto, Portugal

${ }^{3}$ Research Institute of Health and Well-being, Coventry University, UK

${ }^{4}$ Department of Physical Education, Federal Rural University of Pernambuco, Dom Manoel de Medeiros/ PE, Brazil

${ }^{5}$ School of Physical Education, Federal University of Rio Grande do Sul, Porto Alegre/RS, Brazil

${ }^{6}$ Centre for Applied Biological and Exercise Sciences, Coventry University, UK
}

\section{Corresponding Author:}

Clarice Maria de Lucena Martins, Research Centre in Physical Activity, Health and Leisure, Faculty of Sports, Porto University, Porto, Portugal.

Email: claricemartinsufpb@gmail.com 
their FMS and (b) the effects on FMS of reallocating time between PA and sedentary behavior (SB). This was a cross-sectional study, using intervention data with Brazilian low-income preschoolers. We observed Brazilian preschoolers of both sexes $\left(M_{\text {age }}=4.5, S D=0.8\right.$ years-old; I0 I boys $)$ over 10 hours of school-time and objectively assessed their PA and SB with Actigraph wGT3X and their FMS with the Test of Gross Motor Development - Second Edition. We explored the associations between schooltime movement behaviors and FMS and between reallocated school-time movement behaviors and FES using compositional analysis in R (version I.40-I), robCompositions (version 0.92-7), and Imtest (version 0.9-35) packages. This isotemporal reallocation showed that, for manipulative skills, reallocating time $(5,10$, and 15 minutes, respectively) from light PA to SB was associated with increasing skill $(0.14,0.28$, and $0.42 \mathrm{FMS}$ units), raising questions as to whether fine motor activity occurred during SB. Thus, school-time movement significantly predicted FMS, with a modest increase in $\mathrm{SB}$, at the expense of light PA eliciting improved manipulative skills.

\section{Keywords}

motor skills, physical activity, children, preschool

\section{Introduction}

According to the World Health Organization (WHO, 2019), adequate amounts of physical activity (PA), reduced sedentary behavior (SB) and good quantity and quality of sleep (SLP) during early childhood (e.g., 0-5 years) are key behavioral characteristics of positive short and long-term health outcomes (WHO, 2019). For children under age five, PA has been associated with healthy skeletal, cardiometabolic, motor and cognitive skill profiles (Carson et al., 2019). Nonetheless, a large proportion of children worldwide do not engage in sufficient moderate to vigorous physical activity (MVPA) (Berglind \& Tynelius, 2017; Santos et al., 2017), have excessive SB, and do not accrue adequate sleep (Chaput et al., 2016, 2017; De Craemer et al., 2018).

In early childhood, fundamental motor skills (FMS), defined as the basis for more complex movements required to participate in sports, games, or in other PA contexts (Logan et al., 2018), develop through physical maturation, and practice (Goodway et al., 2019). FMS play an essential role in the development of children's movement patterns (Hardy et al., 2012). Therefore, early childhood is a critical period for FMS development, and optimal FMS performance may facilitate subsequent participation in daily and sports activities (Stodden et al., 2008) and help determine future health and academic achievements (Jaakkola et al., 2015). 
Considering that movement behaviors track from childhood to adulthood (Telama, 2009) and that school-time comprises prolonged periods each day for a large number of children (Ward et al., 2010) and provides an infrastructure for facilitating healthy behaviors (Story et al., 2009), the school has long been appointed as a place to enhance children's PA. Young children from low-income families, living in vulnerable zones, spend more than $60 \%$ of their awake time in a preschool setting. Generally speaking, preschoolers from low-income families are less likely to be engaged in other structured PA opportunities (Chang \& Kim, 2017), spend a great amount of time being sedentary (Santana et al., 2017), and engage in a great deal of screen time (Carson et al., 2010). So, for these children, meeting international movement guidelines as described above (WHO, 2019) is highly influenced by the amount of PA and SB, including naps, they accumulate within preschool (Tassitano et al., 2020), meaning that preschool time may also influence their early development. Indeed, facilities for PA in socially vulnerable areas are scarce, and children living in these areas have a greater likelihood of delayed FMS (Nobre et al., 2016). Moreover, a different "quality" of recreational sedentary time, characterized by more time viewing screen media during preschool years, may pose concerns for children's neurobiological development, affecting, in turn, how children play and learn (Horowitz-Kraus \& Hutton, 2018).

Recently, there has been growing support for adopting a research approach based on compositional time for understanding the effect of movement behaviors on health outcomes. In this way, analyses of time spent in various movement behaviors mirror the time-bound 24-hour nature of many international guidelines for PA (WHO, 2019). When considering any singular portion of a behavioral time-bound composition, any theoretical increase or decrease of time spent in one behavior must result in the reduction of of an equal time allocation in remaining behaviors (Aitchison, 1982). Indeed, when considering behaviors as compositionally time-bound, positive health changes have been been achieved by reallocating the time expenditures between these behaviors in varied populations of youth, adults, and the elderly (Biddle et al., 2018; García-Hermoso et al., 2017; Pelclova et al., 2020), respectively. A recent study suggested that replacing a percentage of time spent during school hours being sedentary and in light PA (LPA) with time spent in MVPA may improve FMS among lowincome elementary school-aged children (Burns et al., 2019). However, to date, there has been no empirical study of preschoolers' movement behaviors, or of the impact of substituting time/intensity spent in one activity for another. Furthermore, little is known about how these reallocations might relate to preschoolers FMS. Therefore, our aims in this study were twofold: (a) to examine whether the school-time composition of movement behaviors (e.g., SB and PA) was associated with FMS development, and (b) to investigate predicted 
differences in FMS when a fixed duration of time was reallocated from one movement behavior to another.

\section{Method}

This cross-sectional study relied on baseline data collected from a school-based PA intervention program called "Movement's Cool" that aims to analyze the associations between movement behaviors and health outcomes among lowincome preschoolers.

\section{Participants}

In João Pessoa, Brazil, the preschool public education zone is divided into nine poles in which 86 early childhood education and care services (ECEC) are located. Within those ECECs, 50 institutions have 3-5-year-old children registered, and 10 of these, located in socially vulnerable zones, were previously selected for "Movement's Cool" research. Among a representative number of these ECECs by poles, we randomly selected six for inclusion in this study. This process yielded 573 preschoolers of varying ages, corresponding to the study's general population (Figure 1-Panel A). All six preschools were located in deprived

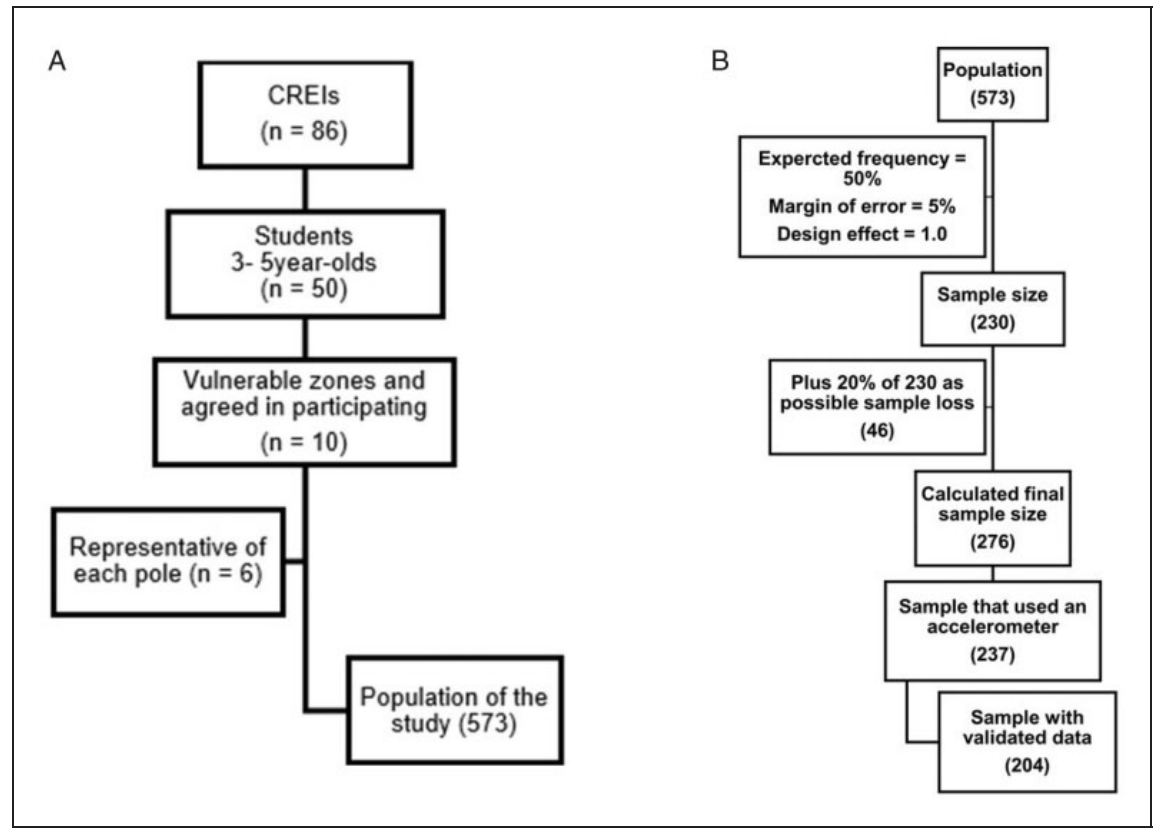

Figure I. CREl's and Sample's Flowchart. 
areas of city (Human Development Index - HDI $=0.7$ ) with low socio-economic status (SES) in which $62.5 \%$ of the mothers or fathers were unemployed and over $45 \%$ of the mothers and $54 \%$ of the fathers had finished the 9 th grade or less. The HDI of the ECEC's areas ranged from 0.3 to 0.5 .

We used $\mathrm{G}^{*}$ Power (3.1.0) to estimate the number of participants required for satisfactory statistical power of 0.85 . We assumed a $95 \%$ confidence interval, $5 \%$ maximum tolerable error, and because there are no reference studies with a similar population, we assumed a large effect size of 1.0. This calculation yielded an estimated required sample size of 230 . We increased this number by $20 \%$, to account for participant attrition and missing data (drop out and hardware failure). Thus, we called and sought informed parental consent from 276 typically developing 3-5 year-old preschool children. As 39 parents chose not to consent for their children to participate, we entered 237 children whose parents provided informed consent into the study and obtained their accelerometer measurements as described below. After applying data reduction criteria (Figure 1-Panel B), there were 204 children $(86.07 \%)$ with valid measurements.

\section{Measurements}

Anthropometric Measures. We determined the children's height (cm) and weight (kg) using a Holtain stadiometer and digitized weighing scales (Seca 708), while the participant was lightly dressed and barefoot, following a standardized procedure (WHO Child Growth Standards, 2009). We calculated the children's body mass index (BMI) by dividing body weight with the squared height in meters $\left(\mathrm{kg} / \mathrm{m}^{2}\right)$.

Physical Activity (PA). We objectively assessed the children's PA using accelerometry (Actigraph, model WGT3-X, Florida). This actigraph has been shown to be a valid instrument for measuring PA in preschoolers (Bornstein et al., 2011). Parents and preschool teachers received verbal and written instructions for the children's correct use of the accelerometer, including its placement and correct positioning. The device initialization, data reduction and analysis were performed using the ActiLife software (Version 6.13.3).

As this study was part of a larger project, the children were instructed to wear the accelerometer on the right hip for seven consecutive days (Wednesday morning to Tuesday afternoon), and parents were allowed to remove the children's device during water-based activities, and during the night, and to re-attach it when children awoke. During preschool time, teachers removed accelerometers at around $11 \mathrm{am}$ for the children's bath and re-fastened them properly just after it. For the purpose of this study, school-time periods were delimited to 7 am to $5 \mathrm{pm}$ on weekdays during at least two days per week.

Accelerometers were setup to measure acceleration at a $100 \mathrm{~Hz}$ sampling rate, using a 15-second epoch length (Cliff et al., 2009), and data was reintegrated to 
60-second epochs for analysis, as ActiGraph counts, considering the vector magnitude. Periods of $\geq 20$ minutes of consecutive zero counts were defined as non-wear time, and data for these periods was removed from the analysis. First day of accelerometer data was also omitted from analysis to avoid unusual readings of movement activity that might be related to the participant's reactivity to first wearing the actigraph device (Esliger et al., 2005). Only days with a minimum of six hours of wear time between $7 \mathrm{am}$ and $5 \mathrm{pm}$ were considered valid. So, data from 33 children were not validated. The wear time ranged from 6 - 10 hours between participants, and the children's mean wear time was 8.5 hours $(S D=2$ hours $)$

We used hourly average values in counts per minute (CPM) to describe the children's daily PA pattern. We estimated the time spent in the commonly defined PA intensity domains of light, moderate and vigorous using the cutpoints proposed by Butte et al. (2014) with light intensity defined as 820 to 3,907 counts, moderate intensity as 3,908 to 6,111 counts and vigorous intensity as $>6,112$ counts. The amount of time spent as sedentary was defined as $\leq 819$ counts sustained for $>10$ consecutive minutes as in Andersen et al. (2017). Habitual PA for the preschool time was defined as the average counts per minute for the time between $7 \mathrm{am}$ and $5 \mathrm{pm}$.

Fundamental Movement Skills (FMS). FMS were measured using the Test of Gross Motor Development - Second Edition (TGMD-2). The TGMD-2 is valid and reliable for use with Brazilian children (Valentini, 2012). It evaluates gross motor performance in children aged 3 - 10 years old, and it consists of two domains: six locomotor skills (run, gallop, hop, leap, jump and slide) and six object control skills (strike, bounce, catch, kick, throw and underhand roll). We administered the TGMD-2 according to the guidelines recommended by Ulrich (2000). Before the assessment of each skill, children were given a visual demonstration of the skill by the researcher, using the correct technique; but they were not told what components of the skill were being assessed. Children were then called individually to perform the skill twice. We gave general encouragement but no verbal feedback on performance during or after the tests. All skills were video-recorded and later assessed by one trained evaluator who did not administer the tests. After viewing each trial, the trained assessor analyzed each skill component. A "1" indicated that the component was present in the performance of the skill for that trial or a " 0 " indicated the component was not present. The video analysis was performed by two expert evaluators. We observed high agreement for the locomotor score: ICC $=0.93$ (95\% CI: $0.69-0.98)$, for the object control score: $\mathrm{ICC}=0.98(95 \%$ CI: $0.93-0.99)$ and for the total motor score (MS): ICC: 0.96 ; (95\% CI: $0.82-$ 0.99). Per the TGMD-2 manual, locomotor and object control scores were based on the presence (one) or absence (zero) of each of the performance criteria. For each subtest, the sum of the raw scores ranged from $0-48$ points. 


\section{Procedure}

Children enrolled in the ECEC's program attended preschool from Monday to Friday, starting at $7 \mathrm{am}$, and finishing at $5 \mathrm{pm}$. In this study, we only analyzed the accelerometer data during the preschool period. Measurements were performed during a three-month period, between March and May 2018. Time in PA and SB was observed between 7am and $5 \mathrm{pm}$ from Wednesday to Tuesday by specialized and trained project staff (PE teachers and graduate students).

All of the schools and parents were informed about the project's protocols and procedures in meetings with the project coordinator (one meeting in each school), and all agreed to participate. The children were drawn from a school list until sufficient data were obtained, according to the proportional distribution calculated for each school, and for each of the ages (3, 4 and 5 years). Sociodemographic data (children's age, birth date, parent's contact and address) were provided by the school administration. Anthropometric (body mass and stature) and movement skills data were collected at pre-schools, and the accelerometer was worn for seven consecutive days by the participating children.

\section{Data Analysis}

As noted earlier, we considered measuring each movement behavior in an isolated manner to be a flawed approach, since movement behaviors are co-exist co-dependently in a time bound analysis in which time spent in one behavior affects, and is effected by time spent in other behaviors during the defined time period (Dumuid et al., 2019). Thus, a compositional data analyses, or CoDA, considers the compositional aspect of movement behaviors within a time block and were conducted in $\mathrm{R}$ (http://cran.r-project.org) using the compositions (version 1.40-1) (van den Boogaart \& Tolosana-Delgado, 2008), robCompositions (version 0.92-7) (Pawlowsky-Glahn \& Buccianti, 2011; Templ et al., 2011), and lmtest (version 0.9-35) software packages.

The school day behavior composition (daily school time spent in SB, LPA, and MVPA) was referred to in terms of central tendency (i.e. the geometric mean of time spent in each component), linearly adjusted so that all components summed to the total school day for interpretation in minutes per day and percentages of the school day (which, for purposes of this study, was bound to 600 minutes, or $7 \mathrm{am}-5 \mathrm{pm}$ ). Multivariate dispersion of the school day composition was described using pairwise log-ratio variation (Aitchison, 1982; Chastin et al., 2015).

We used multiple linear regression models to investigate the relationship between school day activity behavior composition (explanatory variable) and each motor competence tenet (dependent variable). Prior to inclusion in the regression model, the composition was expressed as a set of two isometric log ratio (ilr) co-ordinates. Covariates (age, BMI, and sex) were additionally 
included as explanatory variables. The outcome variables were total motor competence (MC), locomotor skill, and manipulative skill. The ilr multiple linear regression models were further checked for linearity, normality, homoscedasticity, and outlying observations to ensure assumptions were not violated. The significance of the school day activity behavior composition (i.e., the set of ilr coordinates) was examined with the 'car::Anova()' function, which uses Wald Chi squared to calculate Type II tests, according to the principle of marginality, testing each covariate after all others (Fox \& Weisberg, 2018).

The above ilr multiple linear regression models were used to predict differences in the outcome variables associated with the reallocation of a fixed duration of time ( 5 minutes) between two activity behaviors, whilst the third remains unchanged. This was achieved by systematically creating a range of new activity compositions to mimic the reallocation of five minutes between all activity behavior pairs, using the mean composition of the sample as the baseline, or starting composition. The new compositions were expressed as ilr coordinate sets, and each subtracted from the mean composition ilr coordinates, to generate $i l r$ differences. These ilr differences (each representing a 5-minute reallocation between two behaviors) were used in the linear models to determine estimated differences $(95 \%$ CI) in all outcomes. Predictions were repeated for pairwise reallocations of 5,10 , and 15 minutes, respectively. The decision was made to only go up to 15 minutes in reallocations so as to reflect the potential for real or actual change in MVPA. Beyond 15 minutes, there is too high a proportion of MVPA being reallocated and inferences from reallocating such a high proportion of overall MVPA will likely result in distorted outputs. The MATLAB function, alchemist/ternplot (Sandrock \& Afshari, 2016), was used to produce ternary plots with a continuous response surface, where increasing red saturation represents a more favorable outcome, and increasing blue saturation less favorable association with the outcome variable.

\section{Results}

As noted above, 204 preschoolers $\left(M_{\mathrm{age}}=4.51\right.$ years, $S D=0.8 ; M_{\mathrm{BMI}}=18.17$, $\left.S D=3.71 \mathrm{~kg} ; M_{\text {height }}=106.00, S D=7.06 \mathrm{~cm}\right)$ of both sexes (101 boys) gave valid data for the study. Compositional means for SB, LPA, and MVPA, and for locomotor, manipulative and total motor competence scores showed that participants spent $69 \%$ of their school-time being sedentary, and approximately $32 \%$ of the school-period engaged in LPA, with MVPA consuming $7 \%$ of their school-time.

We explored the variability of these data in a variation matrix containing all pair-wise log-ratio variances. A value close to zero suggested that the time spent in SB and PA were highly proportional. For instance, the log variance (Sedentary/LPA) was 0.15 , which reflects the (proportional) relationship or co-dependence between the two behavior types. The highest log-ratio variance 


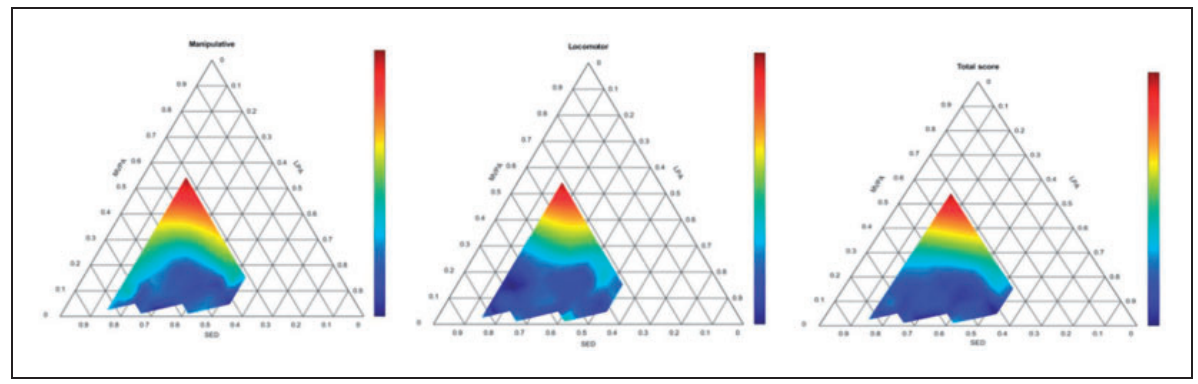

Figure 2. Ternary Plot of PA Composition and FMS Manipulative, Locomotor and Total Motor Competence Skill. Note: The edges of the triangles are the pseudo-time axes, where each grid line represents $10 \%$ of the school-time composition, i.e., $0.1=10 \%$ of 600 $\mathrm{min},=60 \mathrm{~min}$. The continuous response surface is colored according to the manipulative score, where red gradation represents comparably higher scores and blue color gradation represents comparably lower scores.

involved MVPA and SB, suggesting that time spent in MVPA was the least codependent on SB (S1).

When data were considered as a composition, adjusted for age, BMI and sex, the school-time composition significantly predicted the FMS locomotor score $\left(p=0.01 ; r^{2}=0.05\right)$, manipulative score $\left(p<0.0001 ; r^{2}=0.08\right)$, and total MC score $\left(p=0.0002 ; r^{2}=0.09\right)$, respectively. Ternary plots for the PA composition, with a continuous response surface, where increasing red saturation represented a more favorable outcome, and increasing blue saturation equated to a less favorable association with the outcome variables, namely locomotor skill, manipulative skill, and total MC score are shown in Figure 2.

Based on the $95 \%$ CI's, total MC improved 0.18 units higher than the predicted mean when five minutes of preschool time were reallocated from LPA to SB. For manipulative skills, a $0.14,0.28$, and 0.42 -unit increase in relation to the predicted mean was found after reallocating five, 10 and 15 minutes, respectively, of preschool time from LPA to SB (see Table 1).

\section{Discussion}

Prior studies have examined the isotemporal reallocation of movement behaviors and health outcomes in several age groups (Grgic et al., 2018). However, this is the first study of pre-school children to use this method to offer unique insight into whether preschool-time behavior composition was associated with FMS or to investigate predicted differences in FMS when a fixed duration of time was reallocated from one behavior to another. In addition, most prior studies have examined how the substituted time was related to body composition (García-Hermoso et al., 2017), fitness (Fairclough et al., 2017) and 
Table I. Isotemporal Substitutions for 5, 10, and 15-Minute Reallocations.

\begin{tabular}{|c|c|c|c|c|}
\hline & & Total MC & Locomotor & Manipulative \\
\hline Add & Remove & Total $(95 \% \mathrm{Cl})$ & Total $(95 \% \mathrm{Cl})$ & Total $(95 \% \mathrm{Cl})$ \\
\hline \multicolumn{5}{|l|}{5 minutes } \\
\hline Sedentary & Light PA & $0.18 * 0.020 .34$ & $0.04-0.090 .17$ & $0.14 * 0.010 .26$ \\
\hline Sedentary & MVPA & $0.28-0.220 .78$ & $0.22-0.08 \quad 0.5$ I & $0.06-0.240 .36$ \\
\hline Light PA & Sedentary & $-0.18-0.390 .03$ & $-0.04-0.170 .08$ & $-0.14-0.26-0.01$ \\
\hline Light PA & MVPA & $0.10-0.540 .75$ & $0.18-0.210 .56$ & $-0.08-0.460 .31$ \\
\hline MVPA & Sedentary & $-0.26-0.700 .19$ & $-0.20-0.460 .07$ & $-0.06-0.320 .20$ \\
\hline MVPA & Light PA & $-0.08-0.670 .52$ & $-0.16-0.510 .20$ & $0.08-0.270 .43$ \\
\hline \multicolumn{5}{|l|}{10 minutes } \\
\hline Sedentary & Light PA & $0.36-0.070 .79$ & $0.08-0.1$ & $0.28 * 0.0$ \\
\hline Sedentary & MVPA & $0.58-0.49 \quad 1.66$ & $0.46-0.18 \quad 1.10$ & $0.12-0.520 .76$ \\
\hline Light PA & Sedentary & $-0.35-0.770 .07$ & $-0.08-0.330 .17$ & $-0.27-0.52-0.02$ \\
\hline Light PA & MVPA & $0.24-1.131 .60$ & $0.38-0.43 \quad 1.19$ & $-0.15-0.960 .66$ \\
\hline MVPA & Sedentary & $-0.49-1.340 .35$ & $-0.38-0.870 .12$ & $-0.12-0.620 .38$ \\
\hline MVPA & Light PA & $-0.13-1.281 .01$ & $-0.29-0.970 .38$ & $0.16-0.520 .84$ \\
\hline \multicolumn{5}{|l|}{15 minutes } \\
\hline Sedentary & Light PA & $0.54-0.11 \quad 1.19$ & $0.12-0.270 .51$ & $0.42 * 0.030 .81$ \\
\hline Sedentary & MVPA & $0.93-0.832 .68$ & $0.74-0.30 \quad$ ।.78 & $0.18-0.86 \quad 1.22$ \\
\hline Light PA & Sedentary & $-0.53--1.150 .10$ & $-0.12-0.490 .25$ & $-0.40-0.77-0.03$ \\
\hline Light PA & MVPA & $0.41-1.772 .59$ & $0.63-0.66$ I.9I & $-0.2|-| .5|\quad| .08$ \\
\hline MVPA & Sedentary & $-0.72-1.920 .48$ & $-0.54-1.250 .17$ & $-0.18-0.890 .54$ \\
\hline MVPA & Light PA & $-0.17-1.831 .49$ & $-0.42-1.400 .57$ & $0.25-0.74 \quad$ I.23 \\
\hline
\end{tabular}

Note: *Significant at $p<0.05$, based on $95 \% \mathrm{Cl}$. MC: motor competence; MVPA: moderate-to-vigorous physical activity.

cardiometabolic (Macgregor et al., 2019) outcomes in later childhood (up to six year olds) in children from high-income countries. There has been scarce prior data concerning preschoolers from a low-income background. In accord with the aims of our study, we found that our participants spent almost $70 \%$ of their school-time in SB. When the spectrum of behaviors was treated as a composition, time spent in various behaviors significantly predicted locomotor, manipulative, and total MC FMS scores, suggesting that the composition of several behavior types during preschool time may potentiate children's MC.

Children's movement hours were predominantly comprised of SB, consistent with a review of other research regarding PA and SB in preschoolers (Hnatiuk et al., 2014) reporting that the proportion of time spent in MVPA and SB during awake hours ranged from $2-41 \%$ and $34-94 \%$, respectively. O'Brien et al. (2018) observed that time in PA and SB in child-care hours were highly varied and inconsistent between studies, although preschoolers were noted to participate in high rates of SB in this setting. Likewise, different studies have investigated the 
adherence of preschool children to 24-hour movement behaviors, with numerous reports that most children do not meet MVPA recommendations, regardless of the ethnic or geographic context (Berglind \& Tynelius, 2017; Chaput et al., 2017; De Craemer et al., 2018). Evidence on the relationship between PA and FMS in childhood has been equivocal. Thus, it is conceivable that this relationship in young children has been masked by the type of data analysis.

In our isotemporal reallocation analysis, we found increased manipulative skills $(0.14,0.28$, and 0.42 -units) to be associated with reallocating time (five, 10 and 15 minutes, respectively) from LPA to SB. Stamatakis et al. (2013) reported that, for 2-12 year old children, TV viewing, but no other type of screen time, was associated with cardiovascular risk markers independently of PA, and using a single marker of screen time/SB may conceal specific associations. In our study, TV viewing did not feature in the typical pre-school day, as TV was forbidden in the preschool settings for these participants. Since fine-motor developmental tasks are a staple of the preschool curriculum, it will be important to better discern what was taking place during accelerometer-defined SB (Stamatakis et al., 2013).

In similar work conducted with children $\left(M_{\text {age }}=8.4, S D=1.8\right.$ years $)$, Burns et al. (2019) examined the relationships between school-time spent in these behaviors (i.e., SB, LPA and MVPA) and FMS, and these authors showed that replacing SB and LPA with MVPA during school hours was significantly associated with higher FMS total scores. Although reducing time in low intensity activities and increasing time in high intensity activities has been associated with children's improved FMS profiles, our data for preschoolers, based on a time-bound behavior compositional approach, showed only that more SB was associated with better manipulative skills. Among possible reasons for these different results are that: (a) there were methodological differences in our time-based compositional behavior approach to analysis; (b) there was an age influence on the effect of reallocating behavioral activities during school time; and/or (c) there may have been fine motor skill practice occurring preschoolbased SB.

It is important to highlight that although locomotor and object control subscales are reasonably well correlated $(r=0.84-0.96)$ (Cools et al., 2009), they should be differentiated, given their independent importance towards predicting health behaviors (Robinson et al., 2015). The results of this study might suggest that time being sedentary in preschool settings may not be so deleterious, depending upon what fine motor activities may be taking place during periods when there is minimal gross motor movement as detected by actigraph or accelerometers. Thus, we could argue that a "high-quality" SB at pre-schools (i.e. playing with puzzles and blocks, painting) may have a positive impact on manipulative skills. Understanding how and which types and patterns of SB might contribute to development of which specific motor skills should be considered an area for further research exploration. 
Indeed, a focus on manipulative skills is a key consideration in the context of the preschool population. Writing ability in preschoolers first develops as a gross motor activity, where finer movements are controlled by the forearm with power and strength in the shoulder and elbow pivots being central to control of movement (El-Dayem et al., 2015). This is strikingly similar to the developmental process in acquiring overarm throwing skill (Langendorfer et al., 2011), and prior studies have reported significant relationships between gross motor skills and handwriting skills in 5-6 year olds (El-Dayem et al., 2015). Consequently, the use of a shoulder, elbow, wrist pivot is key in early development of writing skill. Although the placement of the accelerometer (left hip) failed to detect any of these shoulder, elbow, or wrist movements, we might speculate that when the hip is quiet, children might still be moving their upper body. In this sense, the link between SB and apparent gross motor skills might be explained, or at least influenced by the fact that in preschoolers, writing, painting, utensil use and similar sedentary tasks tend to be more gross in nature and share some similarities in early developmental trajectory to object manipulation skills such as throwing, as both involve a complex interaction between psychomotor skills, nervous system and muscular strength (Accardo et al., 2013; Hamstra-Bletz \& Blote, 1990).

We can also argue that the sedentary electronic lifestyle of young children, characterized by their frequent use of smartphones (Kabali et al., 2015) may, at least partly, explain the current results, particularly when approximating these patterns to those of preschoolers from high-income countries. In a study with Australian preschoolers, Barnett et al. (2012) showed that the use of interactive and non-interactive electronic games was positively associated with object control competence but had no association with locomotor competence. The use of smartphones is widespread and even part of life among Brazilian low-income families. Assuming that manipulative technologies help increase the manipulative skills to a certain standard, our current results suggest that this competence may be further improved by adding "non-screen" manipulation activities during school hours, especially considering the amount of daily time these children spend in preschools.

Moreover, although the preschool setting may have a meaningful influence on children's motor skills, one should not expect preschool to be the only daily available setting to allow children to be active. Nonetheless, concerning FMS as a product of preschooler's engagement in PA opportunities (Stodden et al., 2008), the contribution of preschool settings to PA engagement is even more important for our participants who had fewer other chances to participate in structured activities.

Our results showed a small but significant improvement of total $\mathrm{MC}$ when five minutes were reallocated from LPA to SB. Nonetheless, for the five-minute substitution, there was a narrow confidence interval for locomotor skills, and it was positive for the manipulative skills. Thus, while the total MC score 
appeared to improve, that improvement was solely due to the changes in manipulative skills. FMS emerge within a dynamic system, consisting of a task performed by a learner in a particular environment (Newell, 1984). In this system, environmental considerations may influence motor development. So, relative to high-income countries, children from low-income families, as the assessed in this study, are less likely to meet WHO SB, and PA guidelines (Kracht et al., 2019), and more likely to have lower FMS proficiency (Bellows et al., 2017), perhaps attributable to a lack of local resources affording fewer developmental learning experiences. Indeed, Playford et al. (2017) indicated that SES was associated with preschool children's fine motor skills but not with their gross motor skills. Similarly, a systematic review found that the parent's economic characteristics were a confirmed correlate of preschoolers' FMS (Iivonen \& Sääkslahti, 2014), although data in this field are still scarce and contradictory.

\section{Limitations of the Study}

While strengths of this study were its consideration of the entire school-day and composite time allocations of behavioral activities as predictors of FMS in preschoolers. some limitations should be highlighted. The compositional approach used here did not discriminate between the various types of activity children might be performing while sedentary, making it difficult, if not impossible, to interpret the meaning of associations between more SB and improved manipulative skills. There is evidence in the literature that classroom naps support learning in preschool children by enhancing memories acquired earlier in the day, compared with equivalent intervals spent awake (Kurdziel et al., 2013). Thus, even naps might be associated with SB. Likewise, the school-time schedule varies according to cultural context. Our study was developed with a specific low-income sample, whose PA opportunities inside and outside school are scarce. Both the age and the social experiences of our participants may challenge the generalizability of our findings to other populations. Yet, our sample's lowincome background mirrors the demographic characteristics of children from other low-income geographical regions, making this an important population to study in its own right. We must also acknowledge that only $86 \%$ of children in this study met the minimum wear-time criteria for accelerometer measurement inclusion. This value is above the average observed in a study with the same age group (Hislop et al., 2016), but it remains difficult to procure sufficient data in these populations, and our usable data was below the level our power analysis suggested was necessary. The strategy we adopted to use colored belts, with images of superheroes, promoted a greater adherence of children to the devicés use, and could be easily adopted in other contexts. Nonetheless, we cannot rule out the possibility that we lacked sufficient statistical power to detect possible other significant relationships between behavioral time allocations in the preschool day and these children's FMS skills. Moreover, the time the 
accelerometer was removed for bath, even accounting for some energy expenditure, was short and may not impact on the overall amount of PA levels. Each child had their bath for approximately $3-5 \mathrm{~min}$, and the accelerometer was quickly fastened after that. The lack of precise information on teacher's diary to support data interpretation is another limitation that should be considered in further studies. Finally, to better understand the relationship between PA and manipulative skills, future investigators may wish to consider an alternative body placement for the accelerometer so as to better measure the extent to which children's gross motor movements reflect upper limb and torso activity.

\section{Conclusion}

The current study presented time based compositional data on school-time behaviors and FMS among preschoolers and highlighted that school-time composition was a significant predictor of FMS manipulative skills. A modest increase in sedentary behavior, at the expense of light physical activity during school-time was associated with a positive change in manipulative skills, raising new questions as to what specific activity took place during sedentary behavior time, measured by hip placement of an accelerometer. There is an urgent need to better discern the effects of different types of sedentary behavior in order to best interpret these findings. We have also detailed limitations of this study and other directions for further research.

Practically, our study contributes to a growth of evidence concerning the importance of movement behaviors during school-time and their implications for preschooler's fundamental movement skills. Interventions to promote the improvement of locomotor and object control skills should focus on reallocating the composition of all movement behaviors within preschool settings. Considering their interrelationships within the confines of a school day, shortperiod time reallocations between movement behaviors can have significant effects. This study illustrates that phenomenon and raises new questions for pedagogical practices and future intervention research.

\section{Declaration of Conflicting Interests}

The author(s) declared no potential conflicts of interest with respect to the research, authorship, and/or publication of this article.

\section{Funding}

The author(s) disclosed receipt of the following financial support for the research, authorship, and/or publication of this article: There was supported by Brazilian Federal Foundation for Support and Evaluation of Graduate Education-CAPES (Grant CAPES-PRINT—88887.369625/2019-00). 


\section{Ethical Approval}

All the Helsinki Declarations' ethical aspects were followed (World Medical Association, 2013). The evaluation methods and procedures were approved by the Research Ethics Committee of Health Science Center of Federal University of Local University (protocol n. 2.727.698), and by the Education Board of the city.

\section{Human Subjects Approval Statement}

All the Helsinki Declarations' ethical aspects were followed (World Medical Association, 2013). The evaluation methods and procedures were approved by the Research Ethics Committee of Health Science Center of Federal University of Local University (protocol n. 2.727.698), and by the Education Board of city.

\section{ORCID iDs}

Anastácio Neco de Souza Filho (D) https://orcid.org/0000-0002-0724-4513

Michael Joseph Duncan (D) https://orcid.org/0000-0002-2016-6580

\section{Supplemental material}

Supplemental material for this article is available online.

\section{References}

Accardo, A. P., Genna, M., \& Borean, M. (2013). Development, maturation and learning influence on handwriting kinematics. Human Movement Science, 32(1), 136-146.

Aitchison, J. (1982). The statistical analysis of compositional data. Journal of the Royal Statistical Society: Series B (Methodological), 44(2), 139-160.

Andersen, E., Borch-Jenssen, J., Ovreas, S., Ellingsen, H., Jorgensen, K. A., \& Moser, T. (2017). Objectively measured physical activity level and sedentary behavior in Norwegian children during a week in preschool. Preventive Medicine Reports, 7, 130-135. https://doi.org/10.1016/j.pmedr.2017.06.003

Barnett, L. M., Hinkley, T., Okely, A. D., Hesketh, K., \& Salmon, J. (2012). Use of electronic games by young children and fundamental movement skills? Perceptual and Motor Skills, 114(3), 1023-1034. https://doi.org/10.2466/10.13.Pms.114.3.1023-1034

Bellows, L. L., Davies, P. L., Courtney, J. B., Gavin, W. J., Johnson, S. L., \& Boles, R. E. (2017). Motor skill development in low-income, at-risk preschoolers: A communitybased longitudinal intervention study. Journal of Science and Medicine in Sport, 20(11), 997-1002. https://doi.org/10.1016/j.jsams.2017.04.003

Berglind, D., \& Tynelius, P. (2017, August 1). Objectively measured physical activity patterns, sedentary time and parent-reported screen-time across the day in fouryear-old Swedish children. BMC Public Health, 18(1), 69. https://doi.org/10.1186/ s12889-017-4600-5

Biddle, G. J. H., Edwardson, C. L., Henson, J., Davies, M. J., Khunti, K., Rowlands, A. V., \& Yates, T. (2018, October 17). Associations of physical behaviours and behavioural reallocations with markers of metabolic health: A compositional data analysis. International Journal of Environmental Research and Public Health, 15(10), 2280. https://doi.org/10.3390/ijerph15102280 
Bornstein, D. B., Beets, M. W., Byun, W., \& McIver, K. (2011). Accelerometer-derived physical activity levels of preschoolers: A meta-analysis. Journal of Science and Medicine in Sport, 14(6), 504-511. https://doi.org/10.1016/j.jsams.2011.05.007

Burns, R. D., Kim, Y., Byun, W., \& Brusseau, T. (2019, July 29). Associations of school day sedentary behavior and physical activity with gross motor skills: Use of compositional data analysis. Journal of Physical Activity and Health, 16(10), 811-817. https:// doi.org/10.1123/jpah.2018-0549

Butte, N. F., Wong, W. W., Lee, J. S., Adolph, A. L., Puyau, M. R., \& Zakeri, I. F. (2014). Prediction of energy expenditure and physical activity in preschoolers. Medicine and Science in Sports and Exercise, 46(6), 1216-1226. https://doi.org/10. 1249/mss.0000000000000209

Carson, V., Spence, J. C., Cutumisu, N., \& Cargill, L. (2010). Association between neighborhood socioeconomic status and screen time among pre-school children: A cross-sectional study. BMC Public Health, 10(1), 367. https://doi.org/10.1186/14712458-10-367

Carson, V., Tremblay, M. S., Chaput, J. P., McGregor, D., \& Chastin, S. (2019). Compositional analyses of the associations between sedentary time, different intensities of physical activity, and cardiometabolic biomarkers among children and youth from the United States. PLoS One, 14(7), e0220009. https://doi.org/10.1371/journal. pone.0220009

Chang, S. H., \& Kim, K. (2017). A review of factors limiting physical activity among young children from low-income families. Journal of Exercise Rehabilitation, 13(4), 375-377. https://doi.org/10.12965/jer.1735060.350

Chaput, J. P., Colley, R. C., Aubert, S., Carson, V., Janssen, I., Roberts, K. C., \& Tremblay, M. S. (2017). Proportion of preschool-aged children meeting the Canadian 24-Hour movement guidelines and associations with adiposity: Results from the Canadian health measures survey. BMC Public Health, 17(S5), 829. https://doi.org/10.1186/s12889-017-4854-y

Chaput, J. P., Gray, C. E., Poitras, V. J., Carson, V., Gruber, R., Olds, T., Weiss, S. K., Connor Gorber, S., Kho, M. E., Sampson, M., Belanger, K., Eryuzlu, S., Callender, L., \& Tremblay, M. S. (2016). Systematic review of the relationships between sleep duration and health indicators in school-aged children and youth. Applied Physiology, Nutrition, and Metabolism= Physiologie Appliquee, Nutrition et Metabolisme, 41(6 Suppl 3), S266-S282. https://doi.org/10.1139/apnm-2015-0627

Chastin, S. F., Palarea-Albaladejo, J., Dontje, M. L., \& Skelton, D. A. (2015). Combined effects of time spent in physical activity, sedentary behaviors and sleep on obesity and cardio-metabolic health markers: A novel compositional data analysis approach. PLoS One, 10(10), e0139984. https://doi.org/10.1371/journal.pone.0139984

Cliff, D. P., Reilly, J. J., \& Okely, A. D. (2009). Sep). methodological considerations in using accelerometers to assess habitual physical activity in children aged 0-5 years. Journal of Science and Medicine in Sport, 12(5), 557-567. https://doi.org/10.1016/j. jsams.2008.10.008

Cools, W., Martelaer, K. D., Samaey, C., \& Andries, C. (2009, June 1). Movement skill assessment of typically developing preschool children: A review of seven movement skill assessment tools. Journal of Sports Science \& Medicine, 8(2), 154-168. 
De Craemer, M., McGregor, D., Androutsos, O., Manios, Y., \& Cardon, G. (2018, October 3). Compliance with 24-h movement behaviour guidelines among Belgian pre-school children: The ToyBox-Study. International Journal of Environmental Research and Public Health, 15(10), 2171. https://doi.org/10.3390/ijerph15102171

Dumuid, D., Pedišić, Ž., Stanford, T. E., Martín-Fernández, J.-A., Hron, K., Maher, C. A., Lewis, L. K., \& Olds, T. (2019). The compositional isotemporal substitution model: A method for estimating changes in a health outcome for reallocation of time between sleep, physical activity and sedentary behaviour. Statistical Methods in Medical Research, 28(3), 846-857. https://doi.org/10.1177/0962280217737805

El-Dayem, T. S. A., Salem, E. E., \& El-Hadidy, E. I. (2015). Correlation between gross motor activities and hand writing skills in elementary school children. Trends in Applied Sciences Research, 10(5), 259-269.

Esliger, D. W., Copeland, J. L., Barnes, J. D., \& Tremblay, M. S. (2005). Standardizing and optimizing the use of accelerometer data for free-living physical activity monitoring. Journal of Physical Activity and Health, 2(3), 366-383.

Fairclough, S. J., Dumuid, D., Taylor, S., Curry, W., McGrane, B., Stratton, G., Maher, C., \& Olds, T. (2017, May 10). Fitness, fatness and the reallocation of time between children's daily movement behaviours: An analysis of compositional data. International Journal of Behavioral Nutrition and Physical Activity, 14(1), 64. https:// doi.org/10.1186/s12966-017-0521-z

Fox, J., \& Weisberg, S. (2018). An R companion to applied regression. SAGE Publications.

García-Hermoso, A., Saavedra, J. M., Ramírez-Vélez, R., Ekelund, U., \& Del PozoCruz, B. (2017). Reallocating sedentary time to moderate-to-vigorous physical activity but not to light-intensity physical activity is effective to reduce adiposity among youths: A systematic review and meta-analysis. Obesity Reviews, 18(9), 1088-1095. https://doi.org/10.1111/obr.12552

Goodway, J. D., Ozmun, J. C., \& Gallahue, D. L. (2019). Understanding motor development: Infants, children, adolescents, adults. Jones \& Bartlett Learning.

Grgic, J., Dumuid, D., Bengoechea, E. G., Shrestha, N., Bauman, A., Olds, T., \& Pedisic, Z. (2018, July 13). Health outcomes associated with reallocations of time between sleep, sedentary behaviour, and physical activity: A systematic scoping review of isotemporal substitution studies. International Journal of Behavioral Nutrition and Physical Activity, 15(1), 69. https://doi.org/10.1186/s12966-018-0691-3

Hamstra-Bletz, L., \& Blote, A. W. (1990). Development of handwriting in primary school: A longitudinal study. Perceptual and Motor Skills, 70(3 Pt 1), 759-770. https://doi.org/10.2466/pms.1990.70.3.759

Hardy, L. L., Reinten-Reynolds, T., Espinel, P., Zask, A., \& Okely, A. D. (2012). Prevalence and correlates of low fundamental movement skill competency in children. Pediatrics, 130(2), e390-e398. https://doi.org/10.1542/peds.2012-0345

Hislop, J., Palmer, N., Anand, P., \& Aldin, T. (2016). Validity of wrist worn accelerometers and comparability between hip and wrist placement sites in estimating physical activity behaviour in preschool children. Physiological Measurement, 37(10), 1701-1714. https://doi.org/10.1088/0967-3334/37/10/1701

Hnatiuk, J. A., Salmon, J., Hinkley, T., Okely, A. D., \& Trost, S. (2014). A review of preschool children's physical activity and sedentary time using objective measures. 
American Journal of Preventive Medicine, 47(4), 487-497. https://doi.org/10.1016/j. amepre.2014.05.042

Horowitz-Kraus, T., \& Hutton, J. S. (2018). Brain connectivity in children is increased by the time they spend reading books and decreased by the length of exposure to screenbased media. Acta Paediatrica (Oslo, Norway: 1992), 107(4), 685-693. https://doi.org/ 10.1111/apa.14176

Iivonen, S., \& Sääkslahti, A. (2014). Preschool children's fundamental motor skills: A review of significant determinants. Early Child Development and Care, 184(7), $1107-1126$.

Jaakkola, T., Hillman, C., Kalaja, S., \& Liukkonen, J. (2015). The associations among fundamental movement skills, self-reported physical activity and academic performance during junior high school in Finland. Journal of Sports Sciences, 33(16), 1719-1729. https://doi.org/10.1080/02640414.2015.1004640

Kabali, H. K., Irigoyen, M. M., Nunez-Davis, R., Budacki, J. G., Mohanty, S. H., Leister, K. P., \& Bonner, R. L. (2015). Exposure and use of mobile media devices by young children. Pediatrics, 136(6), 1044-1050. https://doi.org/10.1542/peds.2015-2151

Kracht, C. L., Webster, E. K., \& Staiano, A. E. (2019, September 6). Sociodemographic differences in young children meeting 24-Hour movement guidelines. Journal of Physical Activity and Health, 16(10), 908-915. https://doi.org/10.1123/jpah.2019-0018

Kurdziel, L., Duclos, K., \& Spencer, R. M. (2013, October 22). Sleep spindles in midday naps enhance learning in preschool children. Proceedings of the National Academy of Sciences of the United States of America, 110(43), 17267-17272. https://doi.org/10. 1073/pnas. 1306418110

Langendorfer, S., Roberton, M. A., \& Stodden, D. (2011). Biomechanical aspects of the development of object projection skills. Paediatric Biomechanics and Motor Control: Theory and Application, 180-206.

Logan, S. W., Ross, S. M., Chee, K., Stodden, D. F., \& Robinson, L. E. (2018). Fundamental motor skills: A systematic review of terminology. Journal of Sports Sciences, 36(7), 781-796. https://doi.org/10.1080/02640414.2017.1340660

Macgregor, A. P., Borghese, M. M., \& Janssen, I. (2019). Is replacing time spent in 1 type of physical activity with another associated with health in children? Applied Physiology, Nutrition, and Metabolism=Physiologie Appliquee, Nutrition et Metabolisme, 44(9), 937-943. https://doi.org/10.1139/apnm-2018-0323

Newell, K. (1984). Physical constraints to development of motor skills. In J. R. Thomas (Ed.), Motor development during childhood and adolescence. Minneapolis : Burgess Pub. Co., c1984. pp. 105-120

Nobre, F. S., Ribeiro Bandeira, P., \& Valentini, N. (2016). Motor delays in socioeconomically disadvantaged children: A bioecological look. Motricidade, 12(2), 59. https://doi.org/10.6063/motricidade.7178

O'Brien, K. T., Vanderloo, L. M., Bruijns, B. A., Truelove, S., \& Tucker, P. (2018, November 21). Physical activity and sedentary time among preschoolers in centrebased childcare: A systematic review. International Journal of Behavioral Nutrition and Physical Activity, 15(1), 117. https://doi.org/10.1186/s12966-018-0745-6

Pawlowsky-Glahn, V., \& Buccianti, A. (2011). Compositional data analysis. Wiley Online Library. 
Pelclova, J., Stefelova, N., Dumuid, D., Pedisic, Z., Hron, K., Gaba, A., Olds, T., Pechova, J., Zajac-Gawlak, I., \& Tlucakova, L. (2020). Are longitudinal reallocations of time between movement behaviours associated with adiposity among elderly women? A compositional isotemporal substitution analysis. International Journal of Obesity, 44(4), 857-864. https://doi.org/10.1038/s41366-019-0514-х

Playford, C. J., Dibben, C., \& Williamson, L. (2017, November 22). Socioeconomic disadvantage, fetal environment and child development: Linked Scottish administrative records based study. International Journal for Equity in Health, 16(1), 203. https:// doi.org/10.1186/s12939-017-0698-4

Robinson, L. E., Stodden, D. F., Barnett, L. M., Lopes, V. P., Logan, S. W., Rodrigues, L. P., \& D'Hondt, E. (2015). Motor competence and its effect on positive developmental trajectories of health. Sports Medicine (Auckland, N.Z.), 45(9), 1273-1284. https://doi.org/10.1007/s40279-015-0351-6

Sandrock, C., \& Afshari, S. (2016). Alchemyst/ternplot. Zenodo. https://doi.org/10.5281/ zenodo/ 166760

Santana, C. C. A., Azevedo, L. B., Cattuzzo, M. T., Hill, J. O., Andrade, L. P., \& Prado, W. L. (2017). Physical fitness and academic performance in youth: A systematic review. Scandinavian Journal of Medicine \& Science in Sports, 27(6), 579-603. https://doi.org/10.1111/sms.12773

Santos, R., Zhang, Z., Pereira, J. R., Sousa-Sa, E., Cliff, D. P., \& Okely, A. D. (2017, November 20). Compliance with the Australian 24-hour movement guidelines for the early years: Associations with weight status. BMC Public Health, 17(S5), 867. https:// doi.org/10.1186/s12889-017-4857-8

Stamatakis, E., Coombs, N., Jago, R., Gama, A., Mourao, I., Nogueira, H., Rosado, V., \& Padez, C. (2013). Type-specific screen time associations with cardiovascular risk markers in children. American Journal of Preventive Medicine, 44(5), 481-488. https:// doi.org/10.1016/j.amepre.2013.01.020

Stodden, D. F., Goodway, J. D., Langendorfer, S. J., Roberton, M. A., Rudisill, M. E., Garcia, C., \& Garcia, L. E. (2008). A developmental perspective on the role of motor skill competence in physical activity: An emergent relationship. Quest, 60(2), 290-306. https://doi.org/10.1080/00336297.2008.10483582

Story, M., Nanney, M. S., \& Schwartz, M. B. (2009). Schools and obesity prevention: Creating school environments and policies to promote healthy eating and physical activity. The Milbank Quarterly, 87(1), 71-100. https://doi.org/10.1111/j.1468-0009. 2009.00548.x

Tassitano, R. M., Weaver, R. G., Tenório, M. C. M., Brazendale, K., \& Beets, M. W. (2020). 2020/12/04). Physical activity and sedentary time of youth in structured settings: A systematic review and meta-analysis. International Journal of Behavioral Nutrition and Physical Activity, 17(1), 160. https://doi.org/10.1186/s12966-02001054-y

Telama, R. (2009). Tracking of physical activity from childhood to adulthood: A review. Obesity Facts, 2(3), 187-195. https://doi.org/10.1159/000222244

Templ, M., Hron, K. and Filzmoser, P. (2011). robCompositions: An R-package for Robust Statistical Analysis of Compositional Data. In V. Pawlowsky-Glahn and A. Buccianti (eds) Compositional Data Analysis. https://doi.org/10.1002/9781119976462. ch25 
Ulrich, D. (2000). Test of gross motor development examiner's manual. https://www.therapro.com/Browse-Category/Gross-Motor-Fine-Motor/TGMD-3-Complete-Kit.html

Valentini, N. C. (2012). Validity and reliability of the TGMD-2 for Brazilian children. Journal of Motor Behavior, 44(4), 275-280. https://doi.org/10.1080/00222895.2012. 700967

van den Boogaart, K. G., \& Tolosana-Delgado, R. (2008). Compositions: A unified R package to analyze compositional data. Computers \& Geosciences, 34(4), 320-338.

Ward, D. S., Vaughn, A., McWilliams, C., \& Hales, D. (2010). Interventions for increasing physical activity at child care. Medicine and Science in Sports and Exercise, 42(3), 526-534. https://doi.org/10.1249/MSS.0b013e3181cea406

WHO Child Growth Standards. (2009). Developmental Medicine and Child Neurology, 51 (12), 1002-1002. https://doi.org/10.1111/j.1469-8749.2009.03503.x

World Health Organization. (2019). Guidelines on physical activity, sedentary behaviour and sleep for children under 5 years of age. WHO Guidelines Approved by the Guidelines Review Committee.

World Medical Association. (2013). World medical association declaration of Helsinki: Ethical principles for medical research involving human subjects. Journal of the American Medical Association, 310(20), 2191.

\section{Author Biographies}

Clarice Maria de Lucena Martins is Professor of Physical Education in the Federal University of Paraíba, BR. Assistant researcher in The Research Centre in Physical activity, health and Leisure, PT, and in the Laboratory for Integrative and Translational Research in Population Health, PT.

Cain Craig Truman Clark is Assistant Professor of statistics and epidemiology in the Research Institute of Health and Well-being, and Centre for Intelligent Healthcare, at Coventry University. In addition, Dr Clark is a Senior Research Fellow at University Hospitals Coventry and Warwickshire, UK.

Rafael Miranda Tassitano is Professor of Physical Education in the Federal Rural University of Pernambuco, BR.

Anastácio Neco de Souza Filhov is a PhD student in the Federal University of Paraíba, BR.

Anelise Reis Gaya is Professor of Physical Education in the Federal University of Rio Grande do Sul, BR.

Michael Joseph Duncan is Professor of Sport and Exercise Science in the School of Life Sciences and Centre for Sport, Exercise and Life Sciences at Coventry University, UK. 